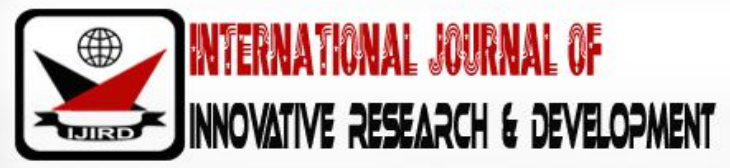

ISSN 2278 - 0211 (Online)

\section{Controlling Attributes in Production Using c and u Control Chart for Attributes}

\author{
A. Ahmed \\ Reader, Department of Mathematical Sciences, Abubakar Tafawa Balewa University, Nigeria \\ 0.0 Agbapuonwu \\ Postgraduate Student, Department of Mathematical Sciences, Abubakar Tafawa Balewa University, Nigeria
}

\begin{abstract}
:
This paper successfully showed how controlling attributes are useful in production process of a company. Many companies face the problem of non-conforming or rather defective items in production. But to minimize the problem of defective items faced by companies, control chart for attribute and data gotten from a selected company was used to analyse the data and all showed to be in control. Therefore, it is seen that control chart for attribute is a very useful tool in a production process because it helps producers to produce products that conforms to a set specification. As we all know a well-packaged product is said to be of best quality.
\end{abstract}

Keywords: Quality, control, charts, defective, response, process, organization, inference, upper control limit, lower control limit

\section{Introduction}

"The statistical control of quality is application of statistical principles and techniques in all stages of design, production, maintenance and service, directed towards the economic satisfaction of demand". The ISO standard defined quantity as the totality of features and characteristics of a product or service that bear on its ability to satisfy stated or implied needs. Quality control is defined as the operational activities that are used to fulfil requirements for quality.

Statistical quality control (SQC) is the application of statistical methodology in quality control. Statistics is concerned with drawing inference from random sample. Hence with sampling and with evaluating samples in order to take adequate decisions on material, products, manufacturing process, organisation etc. Quality control is the use of techniques and activities that compare actual quality performance with goals and define appropriate action in response to any shortfall. It is the process that monitors specific projects results to determine if they comply with relevant standards and identifies different approaches to eliminate the cause for the unsatisfactory performance. There are a couple good tools that can be used to control quality on a product. But for this paper, the control charts for attributes will be used. Control charts is a graphical display of data that illustrates the results of a process over time, the purpose of a control chart is to determine whether a process is in control or out of control over a specified length of time.

\section{Methodology}

Secondary data were obtained from the production record from a selected water company. The method of analysis used is the control chart for attribute. Specifically, c and u control charts. There are two main categories of control charts, those that display attribute data and those that display variable data.

Attribute data refers specifically to category of control chart that displays data that result from counting the number of occurrences or items in a single category of similar items or occurrences. These "counts" data may be expressed as pass/ fail, yes/ no or presence/ absence of a defects.

Variable data refers to the category of control chart that displays resulting from the measurement of a continuous variable. Example of variable data is elapsed time, temperature and radiation dose.

\section{1. c-CHART}

The c-chart also known as control chart for non-conformities. A nonconforming item is a unit of product that does not satisfy one more of the specification for that product. Each specific point at which a specification is not satisfied results in non- 
conforming product. If no standard value of $\mathrm{c}$ is given, then $\mathrm{c}$ may be estimated as the observed average number of nonconformities in a preliminary sample of inspection units $\bar{C}$. Hence, the control chart has parameters defined as

Upper Control Limit (UCL) $=\bar{C}+3 \sqrt{\bar{C}}, \mathrm{CL}=\bar{C}$ and the Lower Control Limit (LCL) $=\bar{C}-3 \sqrt{\bar{C}}$. Where $\bar{C}=\frac{\sum_{i=1}^{m} C i}{m}$ and

$\mathrm{Ci}=$ number of the non-conformities in the ith sample.

$\mathrm{m}=$ number of observations

\section{2. u-CHART}

The u-chart, also known as control chart for defects per units is a type of control chart used to monitor count-type data where the sample size is greater than one, typically, the average number of non-conformities per unit.

The $\mathrm{u}$-chart defers from the c-chart in that, it accounts for the possibility that the number or size of inspection units for which non-conformities are to be counted may vary. The u-chart shows the proportion of non-conforming units in subgroups of varying sizes. Non-conformities are defects or occurrences found in the sampled subgroup.

The control limits are described as:

Upper Control Limit (UCL) $=\bar{u}+3 \sqrt{\frac{\bar{u}}{n}}$. Control Limit $(\mathrm{CL})=\bar{u}$ and the

Lower Control Limit (LCL) $=\bar{u}-3 \sqrt{\frac{\bar{u}}{n}}$ where $U i=C / n$ and

$\mathrm{C}=$ number of defects or non-conformities.

$\mathrm{n}=$ sample size

$\mathrm{m}=$ number of observation, and $\bar{u}=\frac{\sum_{i=1}^{m} u i}{m}$

\subsection{Analysis}

Thirty (30) batches of sachet water were selected from the company's production records. One (1) batch of sachet water equal 100 bags and 30 batches $=3000$ bags. This implies batch inspection of checking every 100 bags of water produced.

\begin{tabular}{|c|c|c|}
\hline Batch Number & Sample & Number of Defectives (In Bags) \\
\hline 1 & 100 Bags & 12 \\
\hline 2 & 100 Bags & 7 \\
\hline 3 & 100 Bags & 5 \\
\hline 4 & 100 Bags & 4 \\
\hline 5 & 100 Bags & 3 \\
\hline 6 & 100 Bags & 5 \\
\hline 7 & 100 Bags & 9 \\
\hline 8 & 100 Bags & 10 \\
\hline 9 & 100 Bags & 14 \\
\hline 10 & 100 Bags & 6 \\
\hline 11 & 100 Bags & 7 \\
\hline 12 & 100 Bags & 2 \\
\hline 13 & 100 Bags & 6 \\
\hline 14 & 100 Bags & 10 \\
\hline 15 & 100 Bags & 8 \\
\hline 16 & 100 Bags & 6 \\
\hline 17 & 100 Bags & 3 \\
\hline 18 & 100 Bags & 1 \\
\hline 19 & 100 Bags & 4 \\
\hline 20 & 100 Bags & 7 \\
\hline 21 & 100 Bags & 6 \\
\hline 22 & 100 Bags & 14 \\
\hline 23 & 100 Bags & 0 \\
\hline 24 & 100 Bags & 9 \\
\hline 25 & 100 Bags & 5 \\
\hline 26 & 100 Bags & 7 \\
\hline 27 & 100 Bags & 4 \\
\hline 28 & 100 Bags & 5 \\
\hline 29 & 100 Bags & 7 \\
\hline 30 & 100 Bags & 12 \\
\hline Total & 3,000 bags & 198 \\
\hline
\end{tabular}

Table 1: Shows the Number of Defectives Obtained from the Sampled Population of the Sachet Water 


\begin{tabular}{|c|c|c|}
\hline Batch Number & Sample & Number of Defectives (Per 5 Bags) \\
\hline 1 & 5 bags & 7 \\
\hline 2 & 5 bags & 4 \\
\hline 3 & 5 bags & 11 \\
\hline 4 & 5 bags & 3 \\
\hline 5 & 5 bags & 6 \\
\hline 6 & 5 bags & 8 \\
\hline 7 & 5 bags & 10 \\
\hline 8 & 5 bags & 5 \\
\hline 9 & 5 bags & 2 \\
\hline 10 & 5 bags & 9 \\
\hline 11 & 5 bags & 1 \\
\hline 12 & 5 bags & 3 \\
\hline 13 & 5 bags & 6 \\
\hline 14 & 5 bags & 3 \\
\hline 15 & 5 bags & 8 \\
\hline 16 & 5 bags & 5 \\
\hline 17 & 5 bags & 4 \\
\hline 18 & 5 bags & 3 \\
\hline 19 & 5 bags & 5 \\
\hline 20 & 5 bags & 4 \\
\hline 21 & 5 bags & 10 \\
\hline 22 & 5 bags & 4 \\
\hline 23 & 5 bags & 6 \\
\hline 24 & 5 bags & 8 \\
\hline 25 & 5 bags & 6 \\
\hline 26 & 5 bags & 6 \\
\hline 27 & 5 bags & 5 \\
\hline 28 & 5 bags & 4 \\
\hline 29 & 5 bags & 12 \\
\hline 30 & 5 bags & 10 \\
\hline Total & 150 bags & 178 \\
\hline
\end{tabular}

Table 2: Shows the Data for the Construction of the Chart for Number of Defectives Per Unit in Sample of 5 Bags of Sachet Water Produced

\subsection{Analysis}

Calculating, we have $\widehat{P} \iota=\frac{D i}{n}$ and $\widehat{U} \iota=\frac{C i}{n}$ we arrived at table 3 below:

\begin{tabular}{|c|c|c|c|}
\hline Batch Number & Sample (N) & Number of Defectives (in Bags) ( $\boldsymbol{D} \boldsymbol{i})$ & Fraction Defectives $\left(\frac{\boldsymbol{D} \boldsymbol{i}}{\boldsymbol{n}}\right)$ \\
\hline 1 & 100 Bags & 12 & 0.12 \\
\hline 2 & 100 Bags & 7 & 0.07 \\
\hline 3 & 100 Bags & 5 & 0.05 \\
\hline 4 & 100 Bags & 4 & 0.04 \\
\hline 5 & 100 Bags & 3 & 0.03 \\
\hline 6 & 100 Bags & 5 & 0.05 \\
\hline 7 & 100 Bags & 9 & 0.09 \\
\hline 8 & 100 Bags & 10 & 0.10 \\
\hline 9 & 100 Bags & 14 & 0.14 \\
\hline 10 & 100 Bags & 6 & 0.06 \\
\hline 11 & 100 Bags & 7 & 0.07 \\
\hline 12 & 100 Bags & 2 & 0.02 \\
\hline 13 & 100 Bags & 6 & 0.06 \\
\hline 14 & 100 Bags & 10 & 0.10 \\
\hline 15 & 100 Bags & 8 & 0.08 \\
\hline
\end{tabular}




\begin{tabular}{|c|c|c|c|}
\hline Batch Number & Sample (N) & Number of Defectives (in Bags) ( $\boldsymbol{D} \boldsymbol{i})$ & Fraction Defectives $\left(\frac{\boldsymbol{D} \boldsymbol{i}}{\boldsymbol{n}}\right)$ \\
\hline 17 & 100 Bags & 3 & 0.03 \\
\hline 18 & 100 Bags & 1 & 0.01 \\
\hline 19 & 100 Bags & 4 & 0.04 \\
\hline 20 & 100 Bags & 7 & 0.07 \\
\hline 21 & 100 Bags & 6 & 0.06 \\
\hline 22 & 100 Bags & 14 & 0.14 \\
\hline 23 & 100 Bags & 0 & 0.00 \\
\hline 24 & 100 Bags & 9 & 0.09 \\
\hline 25 & 100 Bags & 5 & 0.05 \\
\hline 26 & 100 Bags & 7 & 0.07 \\
\hline 27 & 100 Bags & 4 & 0.04 \\
\hline 28 & 100 Bags & 5 & 0.05 \\
\hline 29 & 100 Bags & 7 & 0.07 \\
\hline 30 & 100 Bags & 12 & 0.12 \\
\hline Total & 3,000 bags & 198 & 1.98 \\
\hline
\end{tabular}

Table 3: Fraction Defectives for $\mathrm{N}=100$ Bags

\begin{tabular}{|c|c|c|c|}
\hline Batch Number & Sample & Number of Defectives (Per 5 Bags) & Fraction Defectives $\left(\frac{C i}{n}\right)$ \\
\hline 1 & 5 bags & 7 & 1.4 \\
\hline 2 & 5 bags & 4 & 0.8 \\
\hline 3 & 5 bags & 11 & 2.2 \\
\hline 4 & 5 bags & 3 & 0.6 \\
\hline 5 & 5 bags & 6 & 1.2 \\
\hline 6 & 5 bags & 8 & 1.6 \\
\hline 7 & 5 bags & 10 & 2.0 \\
\hline 8 & 5 bags & 5 & 1.0 \\
\hline 9 & 5 bags & 2 & 0.4 \\
\hline 10 & 5 bags & 9 & 1.8 \\
\hline 11 & 5 bags & 1 & 0.2 \\
\hline 12 & 5 bags & 3 & 0.6 \\
\hline 13 & 5 bags & 6 & 1.2 \\
\hline 14 & 5 bags & 3 & 0.6 \\
\hline 15 & 5 bags & 8 & 1.6 \\
\hline 16 & 5 bags & 5 & 1.0 \\
\hline 17 & 5 bags & 4 & 0.8 \\
\hline 18 & 5 bags & 3 & 0.6 \\
\hline 19 & 5 bags & 5 & 1.0 \\
\hline 20 & 5 bags & 4 & 0.8 \\
\hline 21 & 5 bags & 10 & 2.0 \\
\hline 22 & 5 bags & 4 & 0.8 \\
\hline 23 & 5 bags & 6 & 1.2 \\
\hline 24 & 5 bags & 8 & 1.6 \\
\hline 25 & 5 bags & 6 & 1.2 \\
\hline 26 & 5 bags & 6 & 1.2 \\
\hline 27 & 5 bags & 5 & 1.0 \\
\hline 28 & 5 bags & 4 & 0.8 \\
\hline 29 & 5 bags & 12 & 2.4 \\
\hline 30 & 5 bags & 10 & 2.0 \\
\hline Total & 150 bags & 178 & 35.6 \\
\hline
\end{tabular}

Table 4: Fraction Defectives for $\mathrm{N}=5$ Bags

\section{5. c-Chart}


The Upper Control Limit $(U C L)=\bar{c} \quad+3 \sqrt{\bar{c}} \quad$ with $\quad \bar{c}=\sum_{\mathrm{i}=1}^{\mathrm{m}} \frac{\mathrm{ci}}{\mathrm{m}}=\frac{178}{30} \quad$ implies that $\bar{c}=5.9333 \approx 6, U C L=13$, Control Limit $(C L)=6$ and the Lower Control Limit $(L C L)=\bar{c}-3 \sqrt{\bar{c}}=-1.3484=0$

Since $\mathrm{LCL}$ is negative, $\mathrm{LCL}=0$. Therefore, $\mathrm{UCL}=13, \mathrm{CL}=6, \mathrm{LCL}=0$

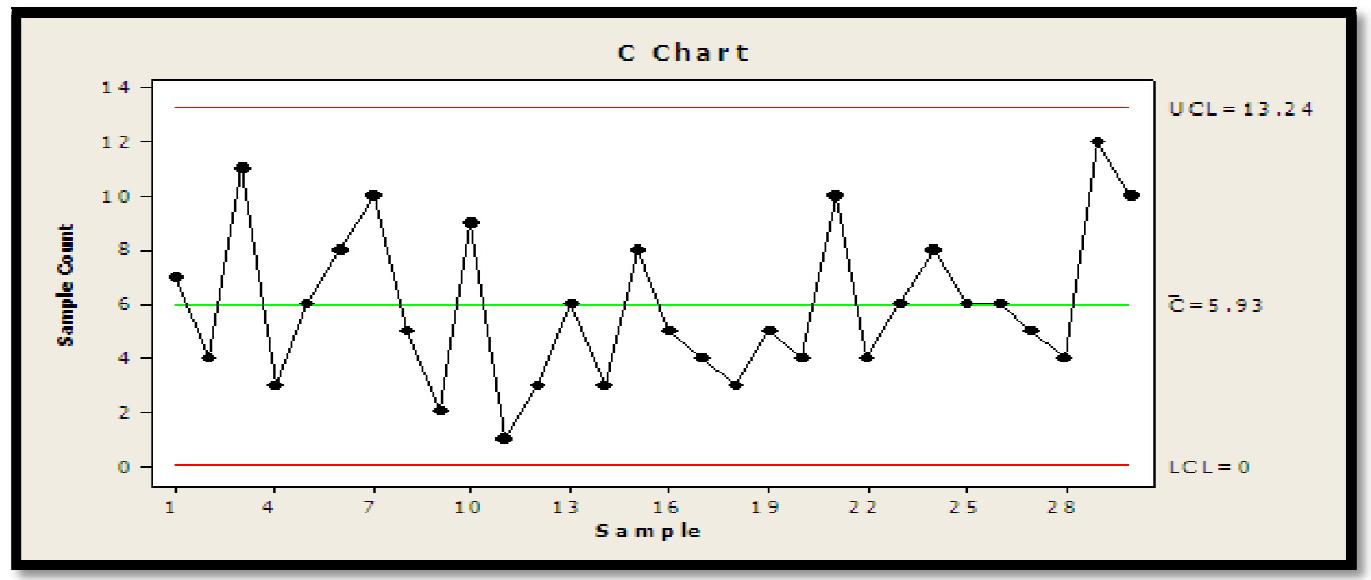

Figure 3: Control Chart for c-Chart

\subsection{The u-Chart}

The Upper Control Limit (UCL)for $\mathrm{u}$ is given as $\mathrm{UCL}=\overline{\mathrm{u}}+3 \sqrt{\frac{\mathrm{u}}{\mathrm{n}}}$ where $\overline{\mathrm{u}}=\sum_{\mathrm{i}=1}^{\mathrm{m}} \frac{\mathrm{ci} / \mathrm{n}}{\mathrm{m}}=\frac{35.6}{30}=1.1867 \approx 1.2$.

Upper Control Limit $=2.7$, Control Limit $=\overline{\mathrm{u}}=1.2$ and Lower Control Limit $($ LCL $)=\overline{\mathrm{u}}-3 \sqrt{\frac{\overline{\mathrm{u}}}{\mathrm{n}}}=-0.2697=0$ Since LCL is negative, $\mathrm{LCL}=0$. Therefore, $\mathrm{UCL}=2.7, \mathrm{CL}=1.2, \mathrm{LCL}=0$.

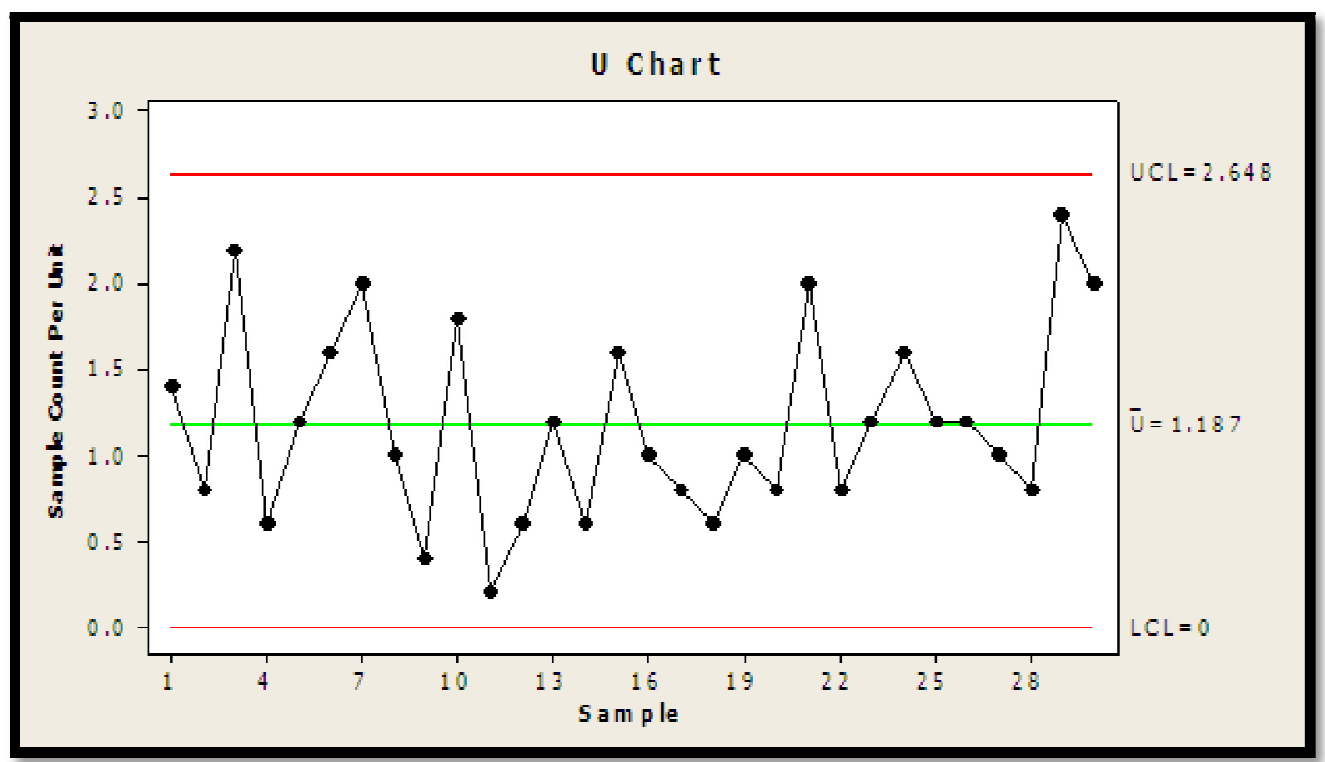

Figure 4: u Control chart

\section{Result}

From the analysis conducted and as presented in figures $1 \& 2$, we can easily see the graphical representation of the data for number of defects and defects per unit drawn. It is therefore evidently clear that the control chart or rather the process is in control. Because all sample points fall within the control limits 


\section{Conclusion}

The purpose of this paper is to determine if the attitude of operators and management towards production affects the production process, to expose the researcher on how quality control is applied in manufacturing industries. All sampled points fall within the control limits, this paper also brought the attention of researchers on how quality control is applied in manufacturing industries to monitor process quality.

\section{References}

i. Abosede, A.J (2000) Sampling And Sampling Techniques In Research Methods In The Social And Management Science.

ii. Deming, W.E (1971) Some Statistical Logic In The Management Of Quality. All India Conference On Quality Control.

iii. Deming, W.E (1986) Out Of The Crisis. Cambridge, Massachusetts

iv. Box,G.E.P, and Luceno, A. (1997). Statistical Control By Monitoring And Feedback Ajustment New York: John Wiley \& Sons [A Comprehensive Study In SPC.]

v. M.A.Abdulazeez,A.Ahmed and F.W.Burari.(2010). The Use of Factorial Design in the Analysis of Global Solar Radiation in Nigeria. Archives of Applied Science Research.2(5),36-44. http:/ / www.scholarsresearchlibrary.com/ archive.html

vi. A.Adamu,S.U.Gulumbe,M.S.Sesay and Abdulkadir Ahmed (2010). Statistical performance of EWMA and MEWMA Quality Control Charts Using Simulation.Journal of institute of Mathematics and Computer Sciences (Computer Science Series).21(3).385-393.

vii. Ahmed,A (2014) The use of Cusum and Ewma techniques to Monitor Hiv/ Aids Epidemic. Jewel Journal of Scientific Research (JJSR) 2(1), 44 - 48. 